\title{
Elderly Men Sexuality in Ouagadougou (Burkina Faso)
}

\section{Brahima Kirakoya ${ }^{1 *}$, Moussa Kabore1, Fanéwendé Aristide Kabore ${ }^{1}$, Abdoul Karim Pare², Abubakar Babagana Mustapha ${ }^{3}$, Ky Bienvenue Désiré1, Barnabé Zango1}

\author{
${ }^{1}$ Department of Urology, Yalgado Ouedraogo University Hospital of Ouagadougou, Ouagadougou, Burkina Faso \\ ${ }^{2}$ Department of Urology, Souro Sanou University Hospital of Bobo Dioulasso, Bobo Dioulasso, Burkina Faso \\ ${ }^{3}$ Department of Surgery, Federal Medical Centre of Nguru, Nguru, Nigeria \\ Email: *kobrahi@yahoo.fr
}

How to cite this paper: Kirakoya, B., Kabore, M., Kabore, F.A., Pare, A.K., Mustapha, A.B., Désiré, K.B. and Zango, B. (2019) Elderly Men Sexuality in Ouagadougou (Burkina Faso). Open Journal of Urology, 9, 62-67.

https://doi.org/10.4236/oju.2019.93007

Received: December 27, 2018

Accepted: March 25, 2019

Published: March 28, 2019

Copyright (C) 2019 by author(s) and Scientific Research Publishing Inc. This work is licensed under the Creative Commons Attribution International License (CC BY 4.0).

http://creativecommons.org/licenses/by/4.0/

\begin{abstract}
Background: In general, sexuality is a taboo subject. It is more so in elderly people, as it is believed that they do not complain about sexual disorder. Objective: To analyse the sexual activity of elderly men in Ouagadougou, Burkina Faso. Methods: This is a descriptive cross-sectional study on the sexual activity of men aged at least 60 years old. The study was carried out in Ouagadougou, Burkina Faso, from $1^{\text {st }}$ June to $31^{\text {st }}$ August 2014. All consenting males who were aged 60 and above at the time of the study were included. Results: We contacted 652 men, but only 200 responded i.e. a response rate of $30.67 \%$. The age of the respondents was between 60 years and 89 years with a mean age of $66.38 \pm 5.72$ years. $80.15 \%$ of the respondents had at least one sexual intercourse in a month. Erection was considered satisfactory or very satisfactory in $45.8 \%(60 / 131)$ of respondents and $63.36 \%$ of them always had orgasm during sexual intercourse. Premature ejaculation was noted in $23.66 \%$ of respondents, while a decline in libido was noted in $82.44 \%$ of them. Conclusion: This study which is the first of its kind in Burkina Faso has helped reveal the importance of sexuality in the lives of elderly men.
\end{abstract}

\section{Keywords}

Elderly Men, Sexuality, Sexual Disorders

\section{Introduction}

Complaining or discussing about sexuality remains a taboo in Burkina Faso. Many people believe that old men should be excluded from discussions about sex. This belief is supported by the fact that aging implies physiological changes that cause a blunting of sexual desire and of sexual activity [1]. So should the el- 
derly man also retire sexually? In developed countries, some studies have addressed the issue of the sexuality of elderly men. These studies revealed that elderly men continue to live their sexuality despite the difficulties they may encounter [2]. In Burkina Faso, even if the subject is taboo, it is also true that there is a real demand for care by the elderly in relation to sexuality, as evidenced by the increasing number of elderly patients, especially the educated ones who complain about it during consultations. Thus, we found it necessary to assess the sexuality of elderly men in the city of Ouagadougou, Burkina Faso.

\section{Methods}

This is a descriptive cross-sectional study concerning the sexuality of men aged at least 60 years old. The study was carried out in Ouagadougou from $1^{\text {st }}$ June to $31^{\text {st }}$ August, 2014. All consenting males who were 60 years and above were included. The data were collected through a pre-established questionnaire and administered in two ways. In the first approach the participant filled the questionnaire himself if he could read and write. In the second approach, the surveyor filled the questionnaire for the participant. The variables studied included the response rate, socio-demographic characteristics, perception about sexual activity, frequency of sexual activity and sexual dysfunction. Sexual dysfunction is disorders of desire, erection and ejaculation. The data collected were analysed using the statistical software SPSS version 21. Categorical variables were presented in frequencies and percentages. The continuous variables were expressed as means \pm standard deviation. The exact Fisher test was used to assess the correlation between two variables and the P-value less than 0.05 was considered statistically significant.

\section{Results}

Over the 652 men contacted, only 200 responded i.e. a response rate of $30.67 \%$. One hundred and thirty one (131) men (65.50\%) filled the questionnaire properly. The age of the respondents ranged from 60 years to 89 years with a mean age of $66.38 \pm 5.72$ years. Among the respondents, 93.9\% (123/131) were married and $64.9 \%(85 / 131)$ were retirees. The literacy rate was $82.44 \%(108 / 131)$. Systemic hypertension was noted in $42.75 \%$ (56/131) of respondents and diabetes mellitus in $8.40 \%$ (11/131) of the respondents (Table 1 ).

Sexuality was a taboo subject for $40.46 \%$ (53/131) of the respondents and $39.69 \%(52 / 131)$ had difficulty to discuss it with their families and friends. For $28.24 \%(37 / 131)$ of respondents there was an age limit where sexual intercourse should be stopped. Among the respondents, $80.15 \%$ (105/131) had at least one sexual intercourse in a month. Heterosexuality was the dominant sexual orientation with $97.71 \%(128 / 131)$. Bisexuals accounted for $1.53 \%(2 / 131)$ and homosexuals $0.76 \%(1 / 131)$. Erection was considered satisfactory or very satisfactory in $45.8 \%(60 / 131)$ of respondents however, $54.2 \%$ (71/131) of the respondents had reported difficulty in having and maintaining a satisfactory erection. The 
quality of erection decreases with age as shown in Table $2(\mathrm{p}$ value $=0.001)$. Among the respondents, $63.36 \%$ (83/131) still had orgasm during sexual intercourses. The frequency of orgasm decreases with age as depicted in Table 3 ( $\mathrm{p}$ value $=0.033)$. Premature ejaculation was noted in $23.66 \%(31 / 131)$ of respondents, while a decline in libido was noted in $82.44 \%$ (108/131) of them.

Only $19.85 \%$ (26/131) of the respondents sought for medical consultation for their sexual problems, $18.32 \%(24 / 131)$ had consulted a traditional health practitioner and $25.19 \%(33 / 131)$ had self-medication before coming to hospital. $76.34 \%(100 / 131)$ of respondents said that the sexual problems they encountered were quite natural.

Table 1. Sociodemographic characteristics $(\mathrm{N}=131)$.

\begin{tabular}{|c|c|c|}
\hline Sociodemographic characteristics & Number of respondents & Percentages (\%) \\
\hline \multicolumn{3}{|l|}{ MARITAL STATUS } \\
\hline \multicolumn{3}{|l|}{ Married } \\
\hline Unmarried & 123 & 93.9 \\
\hline Widow & 4 & 3.05 \\
\hline Divorcee & 3 & 2.29 \\
\hline Divorece & 1 & 0.76 \\
\hline \multicolumn{3}{|l|}{ OCCUPATION } \\
\hline Civil servant & 35 & $20 . / 1$ \\
\hline Trader & 2 & 1.52 \\
\hline Farmer & 3 & 2.29 \\
\hline Retiree & 85 & 64.9 \\
\hline Others & 6 & 4.58 \\
\hline \multicolumn{3}{|l|}{ EDUCATION } \\
\hline Unschooled & 23 & 17.56 \\
\hline Primary & 33 & 25.19 \\
\hline Secondary & 53 & 40.46 \\
\hline Tertiary & 22 & 16.79 \\
\hline \multicolumn{3}{|l|}{ COMOBIDITIES } \\
\hline Systemic hypertension & 30 & 82.10 \\
\hline Diabetes mellitus & 11 & 8.4 \\
\hline Prostate cancer & 3 & 2.29 \\
\hline Benign prostatic hyperplasia & 12 & 9.16 \\
\hline Neurological disorders & 12 & 9.16 \\
\hline Radical prostatectomy & 5 & 3.82 \\
\hline
\end{tabular}

Table 2. Distribution of respondents according to the quality of erection.

\begin{tabular}{cccccc}
\hline \multicolumn{4}{c}{ Age groups (years) } & \multicolumn{4}{c}{ Quality of erection \% (n) } \\
\hline & Very satisfactory & satisfactory & Acceptable & Erection absent & Total \\
\hline$[60-69]$ & $9.9(13)$ & $28.2(37)$ & $32.1(42)$ & $4.6(6)$ & $74.8(98)$ \\
{$[70-79]$} & $2.3(3)$ & $5.3(7)$ & $13(17)$ & $1.5(2)$ & $22.1(29)$ \\
{$[80-89]$} & $0(0)$ & $0(0)$ & $0(0)$ & $3.1(4)$ & $3.1(4)$ \\
Total & $12.2(16)$ & $33.6(44)$ & $45(59)$ & $9.2(12)$ & $100(131)$ \\
\hline
\end{tabular}

Fisher's exact test $=19.247, \mathrm{p}=0.001$. 
Table 3. Distribution of respondents according to the frequency of orgasm.

\begin{tabular}{ccccccc}
\hline \multicolumn{6}{c}{ Age groups (years) } & \multicolumn{5}{c}{ Variation of orgasm \% (n) } \\
\hline & Never & Often & Very often & Always & No answer & Total \\
\hline$[60-69]$ & $3.1(4)$ & $8.4(11)$ & $14.5(19)$ & $48.1(63)$ & $0.8(1)$ & $74.9(98)$ \\
{$[70-79]$} & $0(0)$ & $6.1(8)$ & $2.3(3)$ & $13.7(18)$ & $0(0)$ & $22.1(29)$ \\
{$[80-89]$} & $1.5(2)$ & $0(0)$ & $0(0)$ & $1.5(2)$ & $0(0)$ & $3.0(4)$ \\
Total & $4.6(6)$ & $14.5(19)$ & $16.8(22)$ & $63.3(83)$ & $0.8(1)$ & $100(131)$ \\
\hline
\end{tabular}

Fisher's exact test $=15.619, \mathrm{p}=0.033$.

\section{Discussion}

The questions have been translated into local languages for those who could not read or write. The understanding may be different and the answers may be less sincere than if the questionnaire was filled by the elderly men themselves. However, the use of the pre-test helped to harmonize the questions and made the understanding easy.

The low response rate (30.67\%) in our study is not specific to the African context. Hughes in the USA [3] and Auld et al. [4] in Canada reported response rates of $24.9 \%$ and $42 \%$ respectively. Indeed, in most cultures sexuality remains confidential, and that could explain the reluctance of some people to answer questions regarding sexual activity. In our study, 39.69\% of respondents reported having difficulties to discuss about sex with those around them. On the other hand, in developed countries, the media have greatly contributed to changing the mores and making sexuality less taboo [5].

Does sexual activity die with the advent of old age? It is true that blunting of sexual activity appears with aging. In our study $82.44 \%$ of respondents had a decrease in libido. In the literature, it is unanimously agreed that there is a decline in sexual desire as men get older [1]. Indeed, the age-related decrease in androgen is mostly responsible for the decrease in libido. Sexual activity beyond the fact that it gives pleasures, allows elderly men to remain intimate with their partners. This is very useful at this stage of life where people are not physically very active. The deterioration of sexual activity will impair significantly the quality of conjugal life [6] [7] [8].

This study reveals that elderly men have a sexual activity. In fact, $80.15 \%$ of respondents had at least one sexual intercourse per month. The same observation is made in most studies on the sexuality of the elderly [2] [9] [10] [11]. This sexual activity encounters some difficulties such as erectile dysfunction which was noticed in $54.2 \%$ of respondents in our study. Erectile dysfunction is the most common human sexual pathology in the world. It is the leading cause of decreasing sexual activity in the elderly [12]. Many factors predispose or aggravate erectile dysfunction such as age with its corollaries (atheroma, systemic hypertension, diabetes ...). Our study revealed that there was a statistically significant link between the age of the respondents and the quality of erection $(\mathrm{p}=$ 
$0.001)$.

Another common sexual pathology is premature ejaculation. In our study, its prevalence was $23.66 \%$, a result similar to those of Porst Hartmut [13] and Chew Kew-Kim [14] who reported a prevalence of $25 \%$ and $28 \%$ respectively. Premature ejaculation is usually due to anxiety.

Should the elderly man consult for something he considers as a taboo? Only $19.85 \%$ of the participants had consulted for their sexual problems. This rate is low even in developed countries [10]. These results confirm once again the taboo nature of sexuality for elderly men. In Africa, there is a lack of information on the possibilities of medical assistance. Thus, elderly men in Burkina Faso resort to traditional healers and to self-medication.

\section{Conclusion}

This study is the first of its kind in Burkina Faso; it revealed the importance of sexuality in the life of elderly men. Problems associated with sexuality in the elderly men are numerous and pose a great challenge to the patients and the society at large. The medical profession and public authorities should now take these pathologies into account in the various health development programs.

\section{Conflicts of Interest}

The authors declare no conflicts of interest regarding the publication of this paper.

\section{References}

[1] Colson, M.-H. (2007) Sex-Life after 60: The Beginning of the End, or a New Lease of Life? Sexologies, 16, 91-101. https://doi.org/10.1016/j.sexol.2006.11.001

[2] Kambou, T., Zango, B., Fongang, C., Sombie, I. and Dao, B. (2005) Study of Erectile Dysfuntion in a Population of Young and Sexually Active Men in Burkina Faso. African Journal of Urology, 11, 310-378.

[3] Hughes, A.K. and Wittmann, D. (2015) Aging Sexuality: Knowledge and Perceptions of Preparation among US Primary Care Providers. Journal of Sex \& Marital Therapy, 41, 304-313. https://doi.org/10.1080/0092623X.2014.889056

[4] Auld, R.B. and Brock, G. (2002) Sexuality and Erectile Dysfunction: Results of a National Survey. Journal of Sexual \& Reproductive Medicine, 2, 50-54.

[5] Cour, F. (2013) Societal Evolution of Sexuality. Progrès en Urologie, 23, 832-783. https://doi.org/10.1016/j.purol.2013.03.015

[6] Colson, M.H. and Lemaire, A. (2007) Cardinal Points of Sexuality: Survey on Sexuality in France in 2004. Médecine Sexuelle, 1, 22-25.

[7] Ginsberg, T.B., Pomerantz, S.C. and Kramer-Feeley, V. (2005) Sexuality in Older Adults: Behaviours and Preferences. Age and Ageing, 34, 475-480. https://doi.org/10.1093/ageing/afi143

[8] Seisen, T., Rouprêt, M., Costa, P. and Giuliano, F. (2012) Influence of Aging on Male Sexual Health. Progrès en Urologie, 22, S7-S13. https://doi.org/10.1016/S1166-7087(12)70029-5

[9] Buttaro, T.M., Koeniger-Donohue, R. and Hawkins, J. (2014) Sexuality and Quality 
of Life in Aging: Implications for Practice. The Journal for Nurse Practitioners, 10, 480-485. https://doi.org/10.1016/j.nurpra.2014.04.008

[10] Corona, G., Rastrelli, G., Maseroli, E., Forti, G. and Maggi, M. (2013) Sexual Function of the Ageing Male. Best Practice \& Research Clinical Endocrinology \& Metabolism, 27, 581-601. https://doi.org/10.1016/j.beem.2013.05.007

[11] Gott, M., Hinchliff, S. and Galena, E. (2004) General Practitioner Attitudes to Discussing Sexual Health Issues with Older People. Social Science \& Medicine, 58, 2093-2103. https://doi.org/10.1016/j.socscimed.2003.08.025

[12] Smith, L.J., Mulhall, J.P., Deveci, S., Monaghan, N. and Reid, M. (2007) Sex after Seventy: A Pilot Study of Sexual Function in Older Persons. The Journal of Sexual Medicine, 4, 1247-1253. https://doi.org/10.1111/j.1743-6109.2007.00568.x

[13] Porst, H., Montorsi, F., Rosen, R.C., Gaynor, L., Grupe, S. and Alexander, J. (2007) The Premature Ejaculation Prevalence and Attitudes (PEPA) Survey: Prevalence, Comorbidities, and Professional Help-Seeking. European Urology, 51, 816-824. https://doi.org/10.1016/j.eururo.2006.07.004

[14] Chew, K.-K., Bremner, A., Stuckey, B., Earle, C. and Jamrozik, K. (2009) Sex Life after 65: How Does Erectile Dysfunction Affect Ageing and Elderly Men? The Aging Male, 12, 41-46. https://doi.org/10.1080/13685530802273400 